\title{
Variable effects of temperature on insect herbivory
}

Rising temperatures can influence the top-down control of plant biomass by increasing herbivore metabolic demands. Unfortunately, we know relatively little about the effects of temperature on herbivory rates for most insect herbivores in a given community. Evolutionary history, adaptation to local environments, and dietary factors may lead to variable thermal response curves across different species. Here we characterized the effect of temperature on herbivory rates for 21 herbivore-plant pairs, encompassing 14 herbivore and 12 plant species. We show that overall consumption rates increase with temperature between 20 and $30^{\circ} \mathrm{C}$ but do not increase further with increasing temperature. However, there is substantial variation in thermal responses among individual herbivore-plant pairs at the highest temperatures. Over one third of the herbivore-plant pairs showed declining consumption rates at high temperatures, while an approximately equal number showed increasing consumption rates. Such variation existed even within herbivore species, as some species exhibited idiosyncratic thermal response curves on different host plants. Thus, rising temperatures, particularly with respect to climate change, may have highly variable effects on plant-herbivore interactions and, ultimately, top-down control of plant biomass. 


\section{Variable effects of temperature on insect herbivory}

2 Nathan P. Lemoine ${ }^{1}$, Deron E. Burkepile ${ }^{1}$, John D. Parker ${ }^{2}$

$3 \quad{ }^{1}$ Department of Biological Sciences

4 Florida International University

5 Miami, FL

$6 \quad{ }^{2}$ Smithsonian Environmental Research Center

7 Smithsonian Institution

8 Edgewater, MD 


\section{Introduction}

10 Environmental temperature drives a number of important ecological interactions,

11 including competition, predation, and herbivory, by determining the metabolic rates of

12 ectothermic organisms (Vassuer and McCann 2005, O'Connor et al. 2009, Vucic-Pestic et al.

13 2011). As metabolic demands increase exponentially with rising temperatures, consumers

14 generally either increase food intake or switch to higher quality diets to offset the rising costs of

15 metabolism (O'Connor 2009, Lemoine et al. 2013). As a result, predation and herbivory rates tend

16 to increase exponentially with increased temperature (Hillebrand et al. 2009, Vucic-Pestic et al.

17 2011). However, both consumption rates and fitness can decline precipitously once a species

18 encounters temperatures beyond its thermal optimum (Lemoine and Burkepile 2012). A suite of

19 adaptive and evolutionary factors determine these thermal optima, such that a given consumer

20 community may contain species with considerably different thermal response curves (Angilletta

21 et al. 2004). To date, however, few (if any) studies have examined variation in thermal response

22 curves for a community of co-occurring herbivores (Buckley et al. 2014).

23 Insect herbivores can be an important top-down force in terrestrial ecosystems,

24 controlling plant biomass (Carson and Root 2000), maintaining species diversity (Bagchi et al.

25 2014), reorganizing competitive hierarchies (Kim et al. 2013), and enhancing nutrient cycling

26 (Metcalf et al. 2014). Because insects are ectothermic, their physiological rates, including

27 consumption and growth rates, are directly tied to environmental temperature. By extension, top-

28 down control of plant biomass is also likely to be temperature dependent. Theoretical and

29 experimental studies suggest that herbivory rates should increase exponentially with rising

30 temperatures (O'Connor et al. 2011). One potential shortcoming of theoretical examinations of

31 temperature-driven herbivore-plant interactions is that they do not often incorporate variation in

32 thermal response curves within an assemblage of herbivore species. In part, this is because 
33 thermal response curves for multiple herbivore species on a single host plant remain mostly

34 uncharacterized. Species are often examined singly, and ecologists have focused on a few readily

35 available model species like Spodoptera spp. (Stamp and Yang 1996) and Manduca sexta

36 (Kingsolver and Woods 1998). In contrast, the herbivore guild within a community, or even on a

37 single host plant, can vary from $1-100$ s of species, each with different life histories, climatic

38 niches, evolutionary histories, and dietary needs that may drive vastly different thermal response

39 curves (Buckley et al. 2014).

40 Multiple factors aside from evolutionary history and local adaptation can determine the

41 shape of a species' thermal response curve. For example, plant chemical defenses can become

42 more or less effective at high temperatures depending on the identity of the herbivore, plant, and

43 chemical compounds in question (Stamp and Osier 1998, Stamp et al. 1997). Similarly, different

44 insect species can become more or less nutrient-limited at higher temperatures, which is also

45 contingent on host plant quality (Kingsolver et al. 2006, Kingsolver and Woods 1998, Lemoine et

46 al. 2013). Thermal response curves therefore likely differ among herbivore species and within a

47 single herbivore species utilizing different hosts. Given the interest in predicting the effects of

48 climate change on trophic interactions and community structure (Singer et al. 2013, Urban et al.

49 2012), we sought to determine whether temperature influences herbivory in a predictable manner

50 based on a few easily measured variables of plant nutritional quality.

51 Here, we report thermal response curves of consumption rates for 21 herbivore-plant

52 pairs, encompassing 14 herbivores and 12 plant species (Table 1). We asked two specific

53 questions: (1) what is the extent of within- and among-species variation in thermal response

54 curves of consumption for insect herbivores? and (2) can plant nutritional quality explain

55 variation in thermal response curves? By working with multiple species of both herbivores and

56 plants, we demonstrate that thermal response curves vary substantially both among and within

57 herbivore species. However, we were unable to detect any influence of plant nutritional quality 
on the overall shape of the thermal response curve across taxa, suggesting that thermal response

59 curves are idiosyncratic and highly variable among plant-herbivore pairs.

\section{Methods}

61 All experiments were conducted at the Smithsonian Environmental Research Center (SERC), in

62 Edgewater, MD, USA from June - August 2012. Using laboratory feeding assays, we evaluated

63 the feeding performance of 14 herbivore species from three Orders (Lepidoptera, Coleoptera,

64 Hymenoptera) on 12 plant species (Fig. 1, Table 1). Herbivores were collected by hand from host

65 plants in the forests and fields on the SERC premises throughout the summer. All herbivores were

66 kept in a cage and fed leaves from the plant species on which they were collected. Individuals

67 were used in feeding assays within $24 \mathrm{~h}$ of collection. No individual was used more than once. As

68 herbivores were opportunistically collected, the number of replicates per host plant/temperature

69 combination varied depending on the number of herbivores found (Table S1). Gregarious species

70 (e.g. Hyphantria cuneata) have higher replicate numbers than do rare, non-gregarious species

71 (e.g. Danaus plexippus). A single lepidopteran species could not be identified beyond the

72 Tortricidae family. We focused on folivorous individuals, using larvae from lepidopteran and

73 hymenopteran species and adults only from a single coleopteran species (Chrysochus auratus).

\section{Feeding Assays}

75 In no-choice assays, a single individual was weighed and placed in a single rearing cup with a

76 single, pre-weighed leaf from a potential host plant (see Table 1). Each rearing cup was randomly

77 assigned to one of four temperatures $\left(20^{\circ}, 25^{\circ}, 30^{\circ}\right.$, and $35^{\circ} \mathrm{C}$, see Table $\mathrm{S} 2$ for temperature and

78 light data from each growth chamber) maintained in growth chambers on a 14:10 light:dark

79 cycle. Temperatures were selected to represent a realistic set of temperatures during the spring in 
summer months. Data from a nearby NOAA weather station (Annapolis, MD) indicate that

81 temperatures can range from $20-35^{\circ}$ during the summer months (June - July, Fig. S1). Leaf

82 petioles were placed in water-filled microcentrifuge tubes capped with cotton to prevent

83 desiccation, and we observed no obvious differences in leaf turgor during the assays. After 24

84 hours, herbivores and leaves were reweighed to estimate consumption rates. Feeding assays of

85 this duration have been used to assess herbivore performance and dietary preferences in

86 lepidopterans (Kingsolver and Woods 1998, Kingsolver and Woods 1997) and coleopterans

87 (Gange et al. 2012, Lemoine et al. 2013). We divided all consumption rates by the initial mass of

88 the individual used in the feeding assay to account for variation in body size among replicates.

89 Consumption rates are reported as grams consumed per gram body mass.

Control assays with no herbivores accounted for autogenic change in leaf weight over the

$9124 \mathrm{~h}$ period ( $n=5$ per plant species per temperature). Leaves of all plant species except $L$.

92 styraciflua gained mass over $24 \mathrm{~h}$ in the absence of herbivores. Larger leaves gained more mass

93 than did smaller leaves. We therefore used species-specific equations to correct for autogenic

94 change in leaf mass (Table S3) rather than using mean change in leaf mass across all autogenic

95 controls. Mass-specific autogenic changes, whether positive or negative, were added to leaf final

96 weights. Negative autogenic changes (i.e. plants lost mass in control assays) would therefore

97 lower estimates of consumption and vice versa. In total, we conducted 552 no-choice feeding

98 assays, resulting in 496 observations after removing individuals that died or molted overnight

99 (final replicate numbers for each herbivore/plant/temperature combination given in Table S1).

\section{Plant Traits}

101 To assess the mechanisms by which temperature affected herbivore performance among

102 plant species, we quantified nutritional characteristics of undamaged leaves $(n=3-5)$ of each

103 plant species, all collected from unique individuals. Prior to all nutrient content analyses, leaves 
104 were weighed, dried to a constant mass at $60^{\circ} \mathrm{C}$, and re-weighed to estimate water content. Dried

105 leaf material was ground to a fine powder for carbon $(\mathrm{C})$, nitrogen $(\mathrm{N})$, and phosphorus $(\mathrm{P})$

106 analyses. Percent $\mathrm{C}$ and $\mathrm{N}$ were estimated using an EAI CE-440 elemental analyzer (Exeter

107 Analytics, Coventry, UK). Phosphorus content was determined using dry oxidation-acid

108 hydrolysis extraction followed by colorimetric analysis on a microplate spectrophotometer

109 (PowerWave XS; Biotek, Winooski, VT).

110 Statistical Analyses

111 We used a Bayesian hierarchical model to determine thermal response curves of

112 consumption for each herbivore-plant pairing. This allowed us to estimate parameters for the

113 overall trend in consumption with increasing temperature, parameters for each herbivore-plant

114 pairing, and the impact of plant nutritional quality on these parameters. A multilevel model is

115 particularly appropriate for handling unbalanced data and small sample sizes for some herbivore-

116 plant pairings, but some of the predicted responses for less well-sampled taxa will be pulled

117 heavily towards the overall mean response (Gelman and Hill 2007). Although there could be a

118 phylogenetic signal in the patterns of thermal curves of different insect herbivores, we did not

119 have sufficient replication within genera or families to address this question. Most species were

120 in unique families (only three families had more than one species represented) and all but three

121 species were lepidopterans (Table 1). Thus, we did not incorporate the possibility of a

122 phylogenetic signal into our analyses.

123 Thermal reaction norms of consumption describe the influence of temperature on

124 consumption rates. Regardless of the specific equation used to model a reaction norm, all thermal

125 reaction norms are characterized by a thermal minimum below which consumption is zero, a

126 thermal optimum where consumption rate is maximized and beyond which consumption declines,

127 and a thermal maximum, above which consumption is zero. We modeled the thermal reaction 
128 norm of consumption rates for each herbivore-plant pairing using a quadratic exponential (i.e.

129 Gaussian) curve because such curves often describe thermal reaction norms (Angilletta 2006):

$$
y_{i j}=\exp \left(a_{j}+b_{j} \operatorname{Temp}_{i j}+c_{j} \operatorname{Temp}_{i j}^{2}\right)+\varepsilon_{i j}
$$

130 where $y_{i j}$ is consumption of the $i^{\text {th }}$ observation in the $j^{\text {th }}$ herbivore-plant pair and $\varepsilon_{i j}$ is residual

131 error. We assumed that errors were normally distributed with a constant variance, but the variance

132 was allowed to differ for each curve due to differing numbers of replicates among herbivore-plant

133 pairings. Hereafter, parameters will be referred to as the intercept $(a)$, exponential $(b)$, and

134 Gaussian $(c)$ terms. The intercept $a$ denotes mean consumption rate (since all predictor variables

135 were standardized, see below), the exponential term $b$ denotes the rate at which consumption

136 initially increases with temperature, and the Gaussian term $c$ denotes the extent to which

137 consumption rates level off or decline at high temperatures.

$138 \quad$ Plant nutritional quality can affect the shape of the thermal response curve by influencing

139 any one of the three parameters that determine the shape of the Gaussian curve. Therefore, each

140 parameter (intercept, exponential, and Gaussian) was modeled as function of nitrogen,

141 phosphorus, and water content of the given plant for each herbivore-plant thermal response curve.

142 For example, the exponential term of the $j^{\text {th }}$ curve was a linear function of plant quality:

$$
b_{j}=\mu_{b}+\gamma_{1} N_{j}+\gamma_{2} P_{j}+\gamma_{2} H_{2} O_{j}+\delta_{j}
$$

143 where $\mu_{b}$ is the overall, community-level linear parameter, and $\gamma_{1}, \gamma_{2}$, and $\gamma_{3}$ represent the

144 influence of nitrogen $(\% \mathrm{~N})$, phosphorus $(\% \mathrm{P})$, and water content $\left(\% \mathrm{H}_{2} \mathrm{O}\right)$ respectively on the

145 exponential parameter of the $j^{\text {th }}$ thermal response curve. $\delta_{j}$ is a multivariate normal error term.

146 Thus, mean consumption rate $(a)$, the rate of increase with temperature $(b)$, and the extent of

147 curvature in the thermal response curve $(c)$ were all modeled as linear functions of plant

148 nutritional content. The random effects for each curve (i.e parameters $\left.a_{j}, b_{j}, c_{j}\right)$ were assumed to 
149 come from a multivariate normal distribution, allowing for covariance among parameter

150 estimates.

151 All predictor variables were standardized prior to analysis to speed chain convergence.

152 For all models, four MCMC chains were run for 5,000 'burn-in' iterations to allow for chain

153 convergence. Posterior distributions of each parameter were simulated by saving the $20^{\text {th }}$ sample

154 from an additional 5,000 posterior simulations, resulting in 1,000 independent estimates (250 per

155 chain, with four chains). Chain convergence and autocorrelation were assessed using trace plots

156 and density plots of posterior simulations. Each parameter was given a mildly uninformative

157 prior normal distribution $(N(0,1))$; variance parameters were given uninformative prior uniform

158 distributions $(U(0,100))$. Because predictors were standardized, the magnitude of parameter

159 estimates will be small, such that a standard normal distribution is relatively uninformative. For

160 each parameter, we calculated the $80 \%$ and $95 \%$ Bayesian credible interval (CI) from the

161 posterior simulations. Parameters whose 95\% CI excluded zero were considered highly

162 significant, whereas parameters whose $80 \%$ CI excluded zero were considered marginally

163 significant. If the $80 \%$ CI included zero, we assumed that the parameter had a low probability of

164 being important. All assumptions of normality and homogenous variances were examined using

165 residual plots. All analyses were conducted using Python v2.7. Bayesian models were evaluated

166 using STAN v2.1 (Stan Development Team 2013), accessed via PySTAN. Python code for the

167 hierarchical model is available as Appendix 1. All code and raw data are available on the

168 corresponding author's website ${ }^{1}$ and will be uploaded to the Dryad database ${ }^{2}$.

169 Climate Change Simulations

$11 \mathrm{http}: / /$ www.natelemoine.com

22 http://datadryad.org/ 
171 herbivores interacts with climate change to alter potential top-down control of plant biomass.

172 Thus, we next built a simple model utilizing observed feeding rates and temperatures to estimate

173 cumulative consumption first over one growing season, and then cumulative consumption given

174 two climate change scenarios, $+3^{\circ}$ and $\mathrm{a}+5^{\circ} \mathrm{C}$ increases in temperature, a moderate and severe

175 climate warming scenario, respectively (IPCC 2007). We obtained hourly temperature records for

176 June - August 2013 from the NOAA weather station in Annapolis, MD (Fig. S2). We then used

177 the 1000 posterior draws of observed feeding rates to estimate hourly consumption rates

178 (including parameter uncertainty) for each herbivore-plant combination across the observed

179 temperature range. Most hourly temperature readings were within the $20-35^{\circ} \mathrm{C}$ range used in

180 our experiments (Fig. S2). This yielded 1000 estimates of cumulative consumption for every

181 herbivore-plant pair. We then simulated climate change by adding $3^{\circ}$ and $5^{\circ}$ to hourly temperature 182 records and repeating the above calculations.

183 This method makes several important assumptions: 1) thermal effects of climate change

184 can be approximated by adding a constant increase in temperature to all hourly temperature

185 records, 2) that an individual feeds at a constant rate for the entire season with no variation as the

186 instar grows over time, and 3) that a single individual is responsible for feeding, or multiple non-

187 overlapping individuals immediately replace one another upon dying to maintain a constant

188 consumption rate across the growing season. These assumptions will often not hold true so our

189 method of assessing climate change is a relatively coarse picture of how climate change may

190 affect herbivory rates over the course of an entire season.

\section{Results}


The exponential parameter $(b)$ of overall consumption rates was significantly greater than

193 zero, indicating that overall consumption rates did increase exponentially with temperature (Figs.

194 2, 3). However, the increase was restricted to temperatures between $20^{\circ}$ and $30^{\circ} \mathrm{C}$ (Fig. 1). The

$19595 \%$ CI of the Gaussian parameter (c) narrowly included zero, but the bulk of the posterior

196 distribution for this parameter lay below zero, indicating that overall consumption rates began to

197 level off at temperatures above $30^{\circ} \mathrm{C}(\operatorname{Pr}(<0)=0.96$, Fig. 3). Accordingly, our model predicts

198 relatively little change in overall consumption rates between $30^{\circ}$ and $35^{\circ} \mathrm{C}$ (Fig. 2). Variance in

199 consumption rates among herbivore-plant pairs also increased substantially with rising

200 temperature. At $20^{\circ}$, variance among mean herbivore-plant consumption rates was 0.45 , while at

$20135^{\circ}$ this variance increased to 1.43 . Thus, variability in consumption rates among herbivore-plant

202 pairs increased by over $300 \%$. As a result, at $20^{\circ} \mathrm{C}$ the predicted mean community-level

203 consumption rates lie between $0.44-1.13$ g per day $(95 \% \mathrm{CI})$. Estimates of mean community-

204 level consumption were more uncertain at higher temperatures, lying between $0.93-2.13 \mathrm{~g}$ per

205 day $(95 \% \mathrm{CI})$.

206 Uncertainty regarding overall consumption rates at higher temperatures stems from

207 idiosyncratic thermal response curves among herbivore-plant pairs (Figs. 4, 5). Six herbivore-

208 plant pairs (Arge scapularis - Ulmus rubra, Chrysochus auratus - Apocynum cannibinum,

209 Hyphantria cunea-Acer negundo, H. cunea-Liquidambar styraciflua, Melanophia canadaria

210 - Lindera benzoin, Papilio troilus - S. albidum) had Gaussian parameters (c) that were

211 moderately or significantly different from zero, indicating decreasing consumption rates at higher

212 temperatures (Figs. 4, 5). An additional eleven herbivore-plant pairs (Atteva aurea-Ailanthus

213 altissima, Danaus plexippus - Asclepias syriaca, Epimecis hortaria - L. benzoin, E. hortaria - S.

214 albidum, Euchaetes egle - Asclepias syriaca, Malacosoma americanum-Prunus serotina,

215 Melanophia canadaria-Acer negundo, Nematus tibialis - Robinia pseudoacacia, P. troilus - L.

216 benzoin, Saucrobotys futilalis - A. cannibinum, Unidentified Tortricid - L. benzoin) increased 
217 consumption with warming throughout the entire temperature range, where the exponential

218 parameter $(b)$ was significantly or moderately different from zero. In some cases the parameter

219 value was small enough that the fit was approximately linear (e.g. Epimecis hortaria-Sassafras

220 albidum, Figs. 4, 5). An additional four herbivore-plant combinations (Danaus plexippus - A.

221 syriaca, E. hortaria-Liriodenron tulipifera, Euchaetes egle-Apocynum cannibinum, M.

222 canadria - S. albidum, Papilio polyxense - Foeniculum vulgare) showed no detectable change in

223 consumption rate with increasing temperature.

224 Even within herbivore species, thermal response curves varied considerably. For example,

225 E. hortaria consumption of L. benzoin, and to a lesser extent $S$. albidum, increased exponentially

226 with temperature (Fig. 4). However, E. hortaria consumption of L. tulipifera did not vary

227 significantly over the observed temperatures (Figs. 4, 5). Likewise, P. troilus increased

228 consumption of $L$. benzoin across temperatures, but consumption of $S$. albidum began to decline

229 at $35^{\circ}$ (Fig. 4). We were not able to detect any effect of plant nutritional content on the shape of

230 thermal response curves among herbivore-plant pairs (Fig. 6).

231 High intra- and interspecific variability among thermal response curves for each

232 herbivore-plant pair led to variable effects of increasing temperatures on potential top-down

233 control of plant biomass (Fig. 7). For example, a $3^{\circ} \mathrm{C}$ increase in temperatures resulted in less

234 than a $20 \%$ increase in cumulative consumption for twelve herbivore-plant pairs compared to

235 what is predicted for current temperatures, while leading to a $>30 \%$ increase for four herbivore-

236 plant pairs (Fig. 7). A $5^{\circ} \mathrm{C}$ increase in temperature exacerbated this variability, as five herbivore-

237 plant pairs exhibited $<20 \%$ increase in cumulative consumption and four herbivore-plant pairs

238 exhibited a $>50 \%$ increase (Fig. 7). Further, increased warming from $3^{\circ}$ to $5^{\circ} \mathrm{C}$ had highly

239 variable impacts on cumulative consumption rates among herbivore-plant pairs. For example,

240 Atteva aurea nearly doubled its estimated consumption of Ailanthus altissima as warming

241 increased from $3^{\circ}$ to $5^{\circ} \mathrm{C}$, whereas estimated consumption by Melanophia canadaria was 
242 unaffected by temperature increases beyond $3^{\circ} \mathrm{C}$ (Fig. 7). Thus, high intra- and interspecific

243 variability in the herbivore-plant thermal response curves led to high variability in potential

244 climate change effects on top-down control of plant biomass over an entire growing season.

\section{Discussion}

Temperature influences herbivory rates via direct effects on insect herbivore physiology.

247 However, it is currently unclear how temperature affects top-down control of plant biomass at the

248 community or species level. Our data suggest that the influence of rising temperature on potential

249 top-down control of plant biomass via herbivory depends upon the identity of the herbivore-plant

250 pair under consideration. Such variability in the relationship between consumption rate and

251 temperature will make it difficult to predict the effects of temperature changes, i.e. climate

252 change, on top-down control of plant biomass.

253

Theory predicts that herbivory rates should increase exponentially with rising temperature more quickly than primary production, reducing standing plant biomass at higher temperatures

255 (Gillooly et al. 2001, O'Connor et al. 2009, O'Connor et al. 2011). However, meta-analyses of

256 thermal response curves report substantial variability among species. Indeed, approximately $40 \%$

257 of the thermal response curves examined by Dell et al. (2011) exhibited curvature, wherein the

258 thermal response curve began to decrease at high temperatures. In our study, $33 \%$ of the

259 herbivore-plant pairs exhibited substantial curvature, reducing consumption of plant biomass at

260 high temperatures, thereby contradicting theoretical predictions of exponential increases in top-

261 down control of plant biomass at high temperatures. Often, reduced consumption rates at high

262 temperatures result from metabolic demand exceeding energetic supply, such that energy

263 available for tasks beyond cellular maintenance, such as movement, feeding, or digestion,

264 decreases sharply at high temperature (Somero, 2011). This results in rapid decreases in 
consumer fitness at temperatures beyond an organism's thermal optimum (Lemoine and

266 Burkepile 2012). We show that community-level herbivory rates display the same, albeit much

267 less pronounced, curvature as do some individual species. The slow decline at higher

268 temperatures, rather than a rapid drop-off beyond some threshold value, is a result of species-

269 specific variation in thermal response curves. Almost half (43\%) of plant-herbivore pairings did

270 not show signs of decreased consumption at higher temperature, while one showed evidence of

271 declining consumption beyond $30^{\circ} \mathrm{C}$, leading to no net change in overall consumption rates at

272 higher temperatures.

273 Such variation in thermal response curves makes predicting the effects of temperature

274 changes (i.e. microhabitat variation, seasonal effects, climate change) on herbivore-plant

275 interactions challenging in the absence of species-specific information. Indeed, a generalist

276 herbivore may have as many thermal response curves as host plants (Lemoine et al. 2013). We

277 report similar patterns here. For example, Epimecis hortaria, the tulip tree beauty moth, rapidly

278 increased consumption of both Lindera benzoin and Sassafras albidum with warming, but the

279 increased consumption of S. albidum was much slower. In contrast, E. hortaria showed no

280 relationship between consumption of Liriodendron tulipifera and temperature. Similarly, Papilio

281 troilus increased consumption of both $L$. benzoin and S. albidum with increasing temperature, but

282 consumption of $S$. albidum began to decrease at $35^{\circ} \mathrm{C}$, and consumption of $L$. benzoin showed no

283 curvature.

284 Given the high variation in thermal response curves among herbivore-plant combinations,

285 predicting the effects of climate change on the top-down control of plant biomass remains

286 challenging. Some studies have ascribed a single thermal response curve to herbivore species,

287 demonstrating that plant biomass will decrease in a warming world as herbivory rates outpace

288 primary production ( $\mathrm{O}^{\prime}$ Connor et al. 2011). Our results suggest that using a single consumption-

289 temperature relationship for all herbivores can substantially overestimate the impact of climate 
change on plant biomass. For example, between $20^{\circ}$ and $30^{\circ} \mathrm{C}$, both Chrysochus auratus and

291 Saucrobotys futilalis increased consumption of Apocynum cannibinum. However, at $35^{\circ} \mathrm{C}$.

292 auratus decreased consumption while $S$. futilalis continued to increase consumption, resulting in

293 little change in overall consumption rates on A. cannibinum beyond $30^{\circ} \mathrm{C}$.

294 When we integrated these changes in consumption over a full growing season, we showed

295 that top-down control on plant biomass is likely to increase with increasing temperature but the

296 magnitude of the increase depends on the herbivore-plant combination. Over the course of a

297 summer, simulated warming resulted in $>20 \%$ increase in cumulative consumption for 10

298 herbivore-plant pairs, just under half of the pairings examined. Conversely, simulated climate

299 change resulted in $>40 \%$ increase in cumulative consumption for five herbivore-plant pairs.

300 Overall, the change in consumption ranged from no change to an increase of over $60 \%$. This

301 variability in consumption may explain why studies documenting significant effects of warming

302 on top-down control of plant biomass typically examine one herbivore species (Chase 1996,

303 Barton et al. 2009) while studies focusing on entire herbivore communities report weak or

304 negligible effects of warming (Richardson et al. 2002).

305 Surprisingly, we were unable to detect any influence of plant nutritional quality on the

306 shape of thermal response curves. Based on previous work (Lemoine et al. 2013), we expected

307 consumption rate to increase more rapidly on plants of higher nutritional quality. Conversely,

308 compensatory feeding predicts that consumption rates should increase more rapidly with

309 temperature for plants of low nutritional quality as herbivores attempt to fuel rising metabolic

310 demands (e.g. Williams et al. 1994). Our data suggest that plant nutritional content had little

311 effect on thermal response curves among herbivore species. However, prior work has found that

312 the relationship between temperature and consumption rates within a given species can vary with

313 dietary quality. For example, the Japanese beetle Popillia japonica increased growth and

314 consumption rates at high temperatures only on host plants with high nitrogen and carbon 
315 concentrations (Lemoine et al. 2013). This may also be the case in our data. Within an herbivore

316 species, we can distinguish some patterns related to plant quality. For example, the generalist

317 herbivore Epimecis hortaria increased consumption rapidly with warming only on higher

318 nitrogen plant species. Within a plant species, however, patterns were less clear, as particular

319 herbivore species were equally likely to have unimodal or exponential curves when feeding on

320 the same plant. Thus, across all 21 plant-herbivore pairings, we were unable to detect an overall

321 pattern relating plant quality to multiple thermal reaction norms. Thus, dietary quality may be

322 more important for determining thermal response curves within herbivore species but cannot

323 predict the shape of consumption thermal response curves among herbivore and plant species.

324 We focused on examining herbivore response to increasing temperature while holding

325 plant phytochemistry constant, but rising temperatures might also affect plant phytochemistry.

326 Plant growth rates increase with rising temperatures (Veteli et al. 2002), which could alter

327 nutritional content or concentrations of defensive compounds as plants shuttle more resources

328 into growth (Coley et al. 1985). However, studies have shown that the effects of temperature on

329 plant secondary chemistry are highly idiosyncratic among species (Veteli et al. 2002, Zvereva and

330 Kozlov 2006). Furthermore, although variable temperature can alter nutritional quality within a

331 species, variation caused by temperature is substantially lower than inherent variation among

332 plant species (Aerts et al. 2009). However, the effects of rising temperature on plant chemistry

333 must be considered more completely before applying results such as ours in a climate change

334 context.

335 One potential caveat of our study is small sample size at many herbivore-plant-

336 temperature combinations. Given that we used field-collected organisms, sample size varied

337 considerably depending on the rarity of the species. Common and/or gregarious species, like $E$.

338 hortaria, M. canadaria, and H. cunea, have much higher sample sizes than rare or cryptic

339 species, like D. plexippus and A. scapularis. Thus, some herbivore-plant pairs show considerable 
340 variability in the estimated thermal response curve and, in some cases, the prediction was heavily

341 influenced by the overall response. However, most work regarding the influence of temperature

342 on herbivory and its interaction with diet quality focus on a few readily available lepidopteran

343 herbivores (Kingsolver and Woods 1998, Kingsolver et al. 2006). The influence of temperature

344 on herbivory by the majority of the species reported here was heretofore unknown, and our

345 research adds considerably to the body of work documenting the importance of temperature on

346 rates of herbivory.

347 In summary, we show that herbivory, and therefore potential top-down control of plant

348 biomass, is highly contingent upon environmental temperature. While theoretical predictions

349 suggest that climate change might increase top-down control of plant biomass, our results

350 indicate that the effects of temperature on herbivory rates are highly variable. A single plant

351 species might experience more or less herbivory at higher temperatures, depending on the

352 identity of the herbivores present. Insects often control plant community structure (Carson and

353 Root 2000) and dominance hierarchies among plant species (Kim et al. 2013). Thus, studies

354 documenting the species-specific effects of temperature on insect herbivory levels will be crucial

355 to understanding how climate change might affect community composition in the plant-herbivore

356 assemblages of the future.

\section{Acknowledgements}

358 We would like to thank W. Drews, J. Shue, S. Cook-Patton, and A. Shantz for help collecting

359 insects, running feeding assays, and insights on the manuscript.

\section{References}


361

362

363

364

365

366

367

368

369

370

371

372

373

374

375

376

377

378

379

380

381

382

383

384

385

386

387

388

389

390

391

392

393

394

395

396

397

398

399

400

Aerts, R., Callaghan, T. V., Dorrepaal, E., van Logtestijn, R. S. P., and Cornelissen, J. H. C. (2009) Seasonal climate manipulations result in species-specific changes in leaf nutrient levels and isotopic composition in a sub-arctic bog. Functional Ecology 23:680-688.

Angilletta, M. J. (2006) Estimating and comparing thermal performance curves. Journal of Thermal Biology 31:541-545.

Angilletta, M. J. (2009) Thermal adaptation: A theoretical and empirical synthesis. Oxford University Press, New York

Angilletta, M. J., Steury, T. D., and Sears, M. W. (2004) Temperature, Growth Rate, and Body Size in Ectotherms: Fitting Pieces of a Life-History Puzzle1. Integrative and Comparative Biology 44:498-509.

Bagchi, R., Gallery, R. E., Gripenberg, S., Gurr, S. J., Narayan, L., Addis, C. E., Freckleton, R. P., and Lewis, O. T. (2014) Pathogens and insect herbivores drive rainforest plant diversity and composition. Nature :doi: 10.1038/nature12911.

Barton, B. T., Beckerman, A. P., and Schmitz, O. J. (2009) Climate warming strengthens indirect interactions in an old-field food web. Ecology 90:2346-2351.

Buckley, L. B., Nufio, C. R., and Kingsolver, J. G. (2014) Phenotypic clines, energy balances and ecological responses to climate change. Journal of Animal Ecology 83:41-50.

Carson, W. P. and Root, R. B. (2000) Herbivory and plant species coexistence: community regulation by an outbreaking phytophagous insect. Ecological Monographs 70:73-99.

Chase, J. M. (1996) Abiotic controls of trophic cascades in a simple grassland food chain. Oikos 77:495-506.

Coley, P. D., Bryant, J. P., and Chapin, F. S. (1985) Resource availability and plant antiherbivore defense. Science 230:895-899.

Dell, A. I., Pawar, S., and Savage, V. M. (2011) Systematic variation in the temperature dependence of physiological and ecological traits. Proceedings of the National Academy of Science USA 108:10591-10596.

Gange, A. C., Eschen, R., Wearn, J. A., Thawer, A., and Sutton, B. C. (2012) Differential effects of foliar endophytic fungi on insect herbivores attacking a herbaceous plant. Oecologia 168:1023-1031.

Gelman, A. and Hill, J. (2007) Data Analysis Using Regression and Multilevel/Hierarchical Models. Cambridge University Press, New York

Gillooly, J. F., Brown, J. H., West, G. B., Savage, V. M., and Charnov, E. L. (2001) Effects of size and temperature on metabolic rate. Science 293:2248-2251.

Hillebrand, H., Borer, E. T., Bracken, M. E. S., Cardinale, B. J., Cebrian, J., Cleland, E. E., Elser, J. J., Gruner, D. S., Harpole, W. S., Ngai, J. T., Sandin, S., Seabloom, E. W., Shurin, J. B., Smith, J. E., and Smith, M. D. (2009) Herbivore metabolism and stoichiometry each constrain herbivory at different organizational scales across ecosystems. Ecology Letters 12:516-527.

IPCC (2007) Climate change 2007: synthesis report. United Nations Environmental Programme.

Kim, T. M., Underwood, N., and Inouye, B. D. (2013) Insect herbivores change the outcome of plant competition through both inter- and intraspecific processes. Ecology 94:1753-1763. 
401

402

403

404

405

406

407

408

409

410

411

412

413

414

415

416

417

418

419

420

421

422

423

424

425

426

427

428

429

430

431

432

433

434

435

436

437

438

439

440
Kingsolver, J. G. and Woods, H. A. (1998) Interactions of temperature and dietary protein concentration in growth and feeding of Manduca sexta caterpillars. Physiological Entomology 23:354-359.

Kingsolver, J. G. and Woods, H. A. (1997) Thermal sensitivity of growth and feeding in Manduca sexta caterpillars. Physiological Zoology 70:631-638.

Kingsolver, J. G., Schlichta, G., Ragland, G. J., and Massie, K. R. (2006) Thermal reaction norms for caterpillar growth depend on diet. Evolutionary Ecology Research 8:705-715.

Lemoine, N. P. and Burkepile, D. E. (2012) Temperature-induced mismatches between consumption and metabolism reduce consumer fitness. Ecology 93:2483-2489.

Lemoine, N. P., Drews, W. A., Burkepile, D. E., and Parker, J. D. (2013) Increased temperature alters feeding behavior of a generalist herbivore. Oikos 122:1669-1678.

Metcalf, D. B., Asner, G. P., Martin, R. E., Espejo, J. E. S., Huasco, W. H., Amézquita, F. F. F., Carranza-Jimenez, L., Cabrera, D. F. G., Baca, L. D., Sinca, F., Quispe, L. P. H., Taype, I. A., Mora, L. E., Dávila, A. R., Solórzano, M. M., Vilca, B. L. P., Román, J. M. L., Bustios, P. C. G., Revilla, N. S., Tupayachi, R., Girardin, C. A. J., Doughty, C. E., and Malhi, Y. (2014) Herbivory makes major contributions to ecosystem carbon and nutrient cycling in tropical forests. Ecology Letters 17:324-332.

O'Connor, M. I. (2009) Warming strengthens an herbivore-plant interaction. Ecology 90:388-398.

O'Connor, M. I., Piehler, M. F., Leech, D. M., Anton, A., and Bruno, J. F. (2009) Warming and resource availability shift food web structure and metabolism. PLOS Biology 7:e1000178.

O'Connor, M. I., Gilbert, B., and Brown, C. J. (2011) Theoretical predictions for how temperature affects the dynamics of interacting herbivores and plants. The American Naturalist 178:626638 .

Richardson, S. J., Press, M. C., Parsons, A. N., and Hartley, S. E. (2002) How do nutrients and warming impact plant communities and their insect herbivores? A 9-year study from a subArctic heath. Journal of Ecology 90:544-556.

Singer, A., Travis, J. M. J., and Johst, K. (2013) Interspecific interactions affect species and community responses to climate shifts. Oikos 122:358-366.

Somero, G. N. (2011) Comparative physiology: a "crystal ball" for predicting consequences of global change. American Journal of Physiology: Regulatory, Integrative and Comparative Physiology 301:R1-R14.

Stamp, N. E. and Osier, T. L. (1998) Response of five insect herbivores to multiple allelochemicals under fluctuating temperatures. Entomologia Experimentalis et Applicata 88:81-96.

Stamp, N. E. and Yang, Y. (1996) Response of insect herbivores to multiple allelochemicals under different thermal regimes. Ecology 77:1088-1102.

Stamp, N. E., Yang, Y., and Osier, T. L. (1997) Response of an insect predator to prey fed multiple allelochemicals under representative thermal regimes. Ecology 78:203-214.

Stan Development Team (2013) Stan: A C++ library for probability and sampling. http://mcstan.org/. 
441 Urban, M. C., Tewksbury, J. J., and Sheldon, K. S. (2012) On a collision course: competition and dispersal differences create no-analogue communities and cause extinctions during climate change. Proceedings of the Royal Society B: Biological Sciences 279:2072-2080.

Vassuer, D. A. and McCann, K. S. (2005) A mechanistic approach for modeling temperature-

446

447

448

449 dependent consumer-resource dynamics. The American Naturalist 166:184-198.

Veteli, T. O., Kuokkanen, K., Julkunen-Tiitto, R., Roininen, H., and Tahvanainen, J. (2002) Effects of elevated $\mathrm{CO}_{2}$ and temperature on plant growth and herbivore defensive chemistry. Global Change Biology 8:1240-1252.

Vucic-Pestic, O., Ehnes, R. B., Rall, B. C., and Brose, U. (2011) Warming up the system: higher predator feeding rates but lower energetic efficiencies. Global Change Biology 17:1301-1310.

451 Williams, R. S., Lincoln, D. E., and Thomas, R. B. (1994) Loblolly pine grown under elevated $452 \quad \mathrm{CO}_{2}$ affects early instar pine sawfly performance. Oecologia 98:64-71.

453 Zvereva, E. L. and Kozlov, M. V. (2006) Consequences of simultaneous elevation of carbon 454 dioxide and temperature for plant-herbivore interactions: a metaanalysis. Global Change 455 Biology 12:27-41. 


\section{Figure 1}

Chrysochus auratus

Chrysochus auratus, the dogbane beetle, feeding on Apocynum cannabinum 


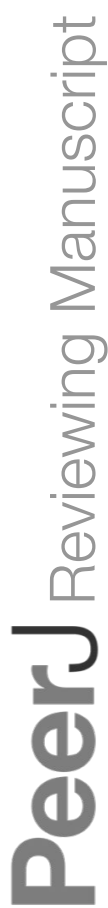

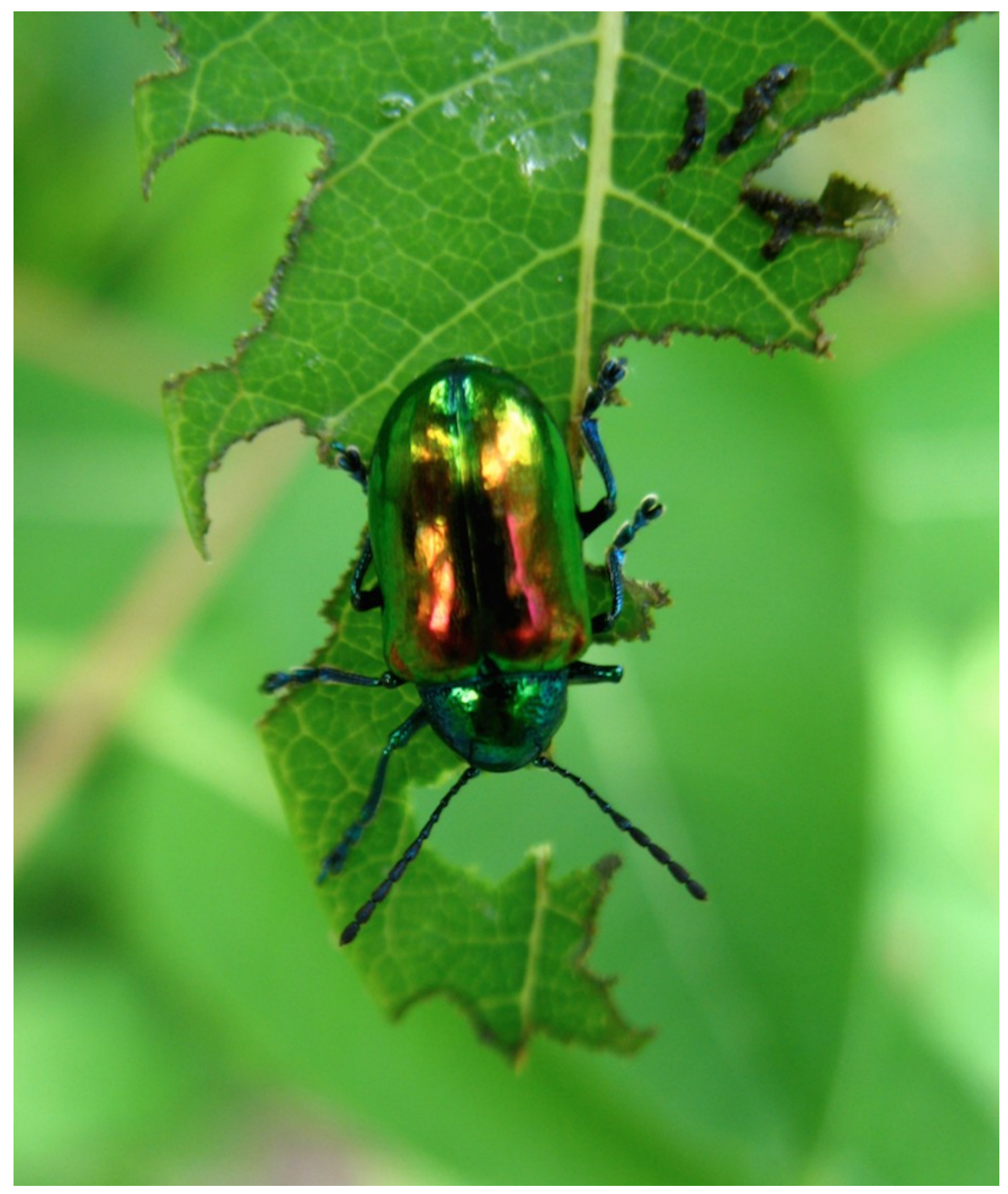




\section{Figure 2}

Effect of temperature on overall consumption rates

Boxplot and predictions of overall consumption rates. Boxes depict the mean consumption rate of each herbivore-plant pair at that temperature ( $n=21$ per box). Shaded area represents the $80 \%$ (dark grey) and $95 \%$ (light grey) credible interval of the prediction. Line shows the median posterior prediction.

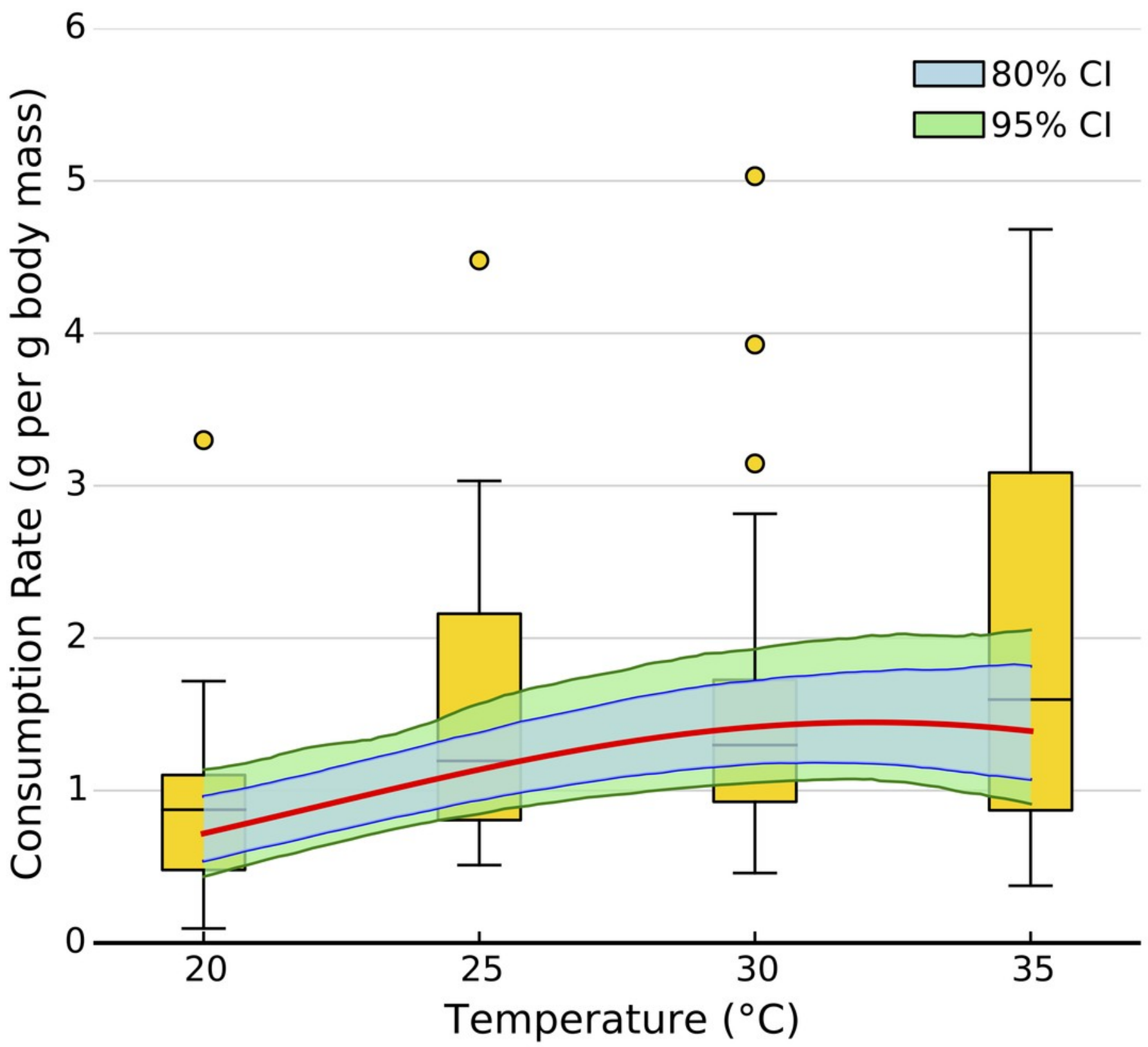




\section{Figure 3}

Parameter estimates of overall consumption rates

Posterior estimates of the parameters of community-level consumption rates. Points represent the median estimate, while lines show the 80\% (thick line) and 95\% (thin line) $\mathrm{Cl}$.

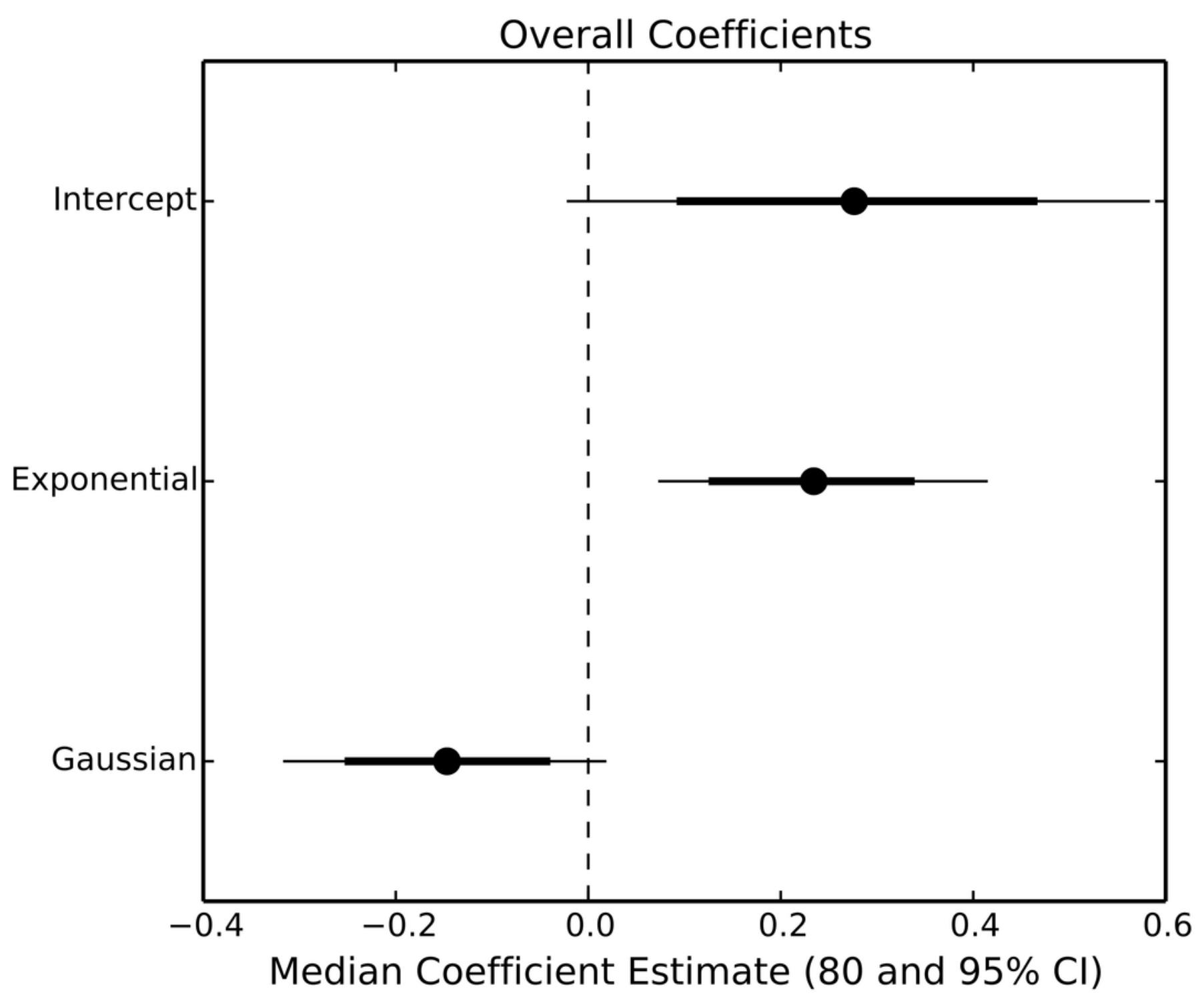




\section{Figure 4}

Effect of temperature on consumption rates for each herbivore-plant pair

Thermal response curves for each herbivore-plant pair. Thick line shows the median posterior estimate, shaded area shows the $95 \%$ confidence interval. Solid lines are significant at the $95 \%$ level, while dotted lines are significant at the $80 \%$ level. In some cases, a dotted line has a highly significant linear term but a moderately significant quadratic term (e.g. Hyphantrea cunea - Liquidambar styraciflua, see Figure 4). Points depict mean consumption rates ( \pm 1 S.E.). Points are weighted by sample size, such that larger points contain more observations, to show how predictions for low sample sizes are pulled towards the overall response. 

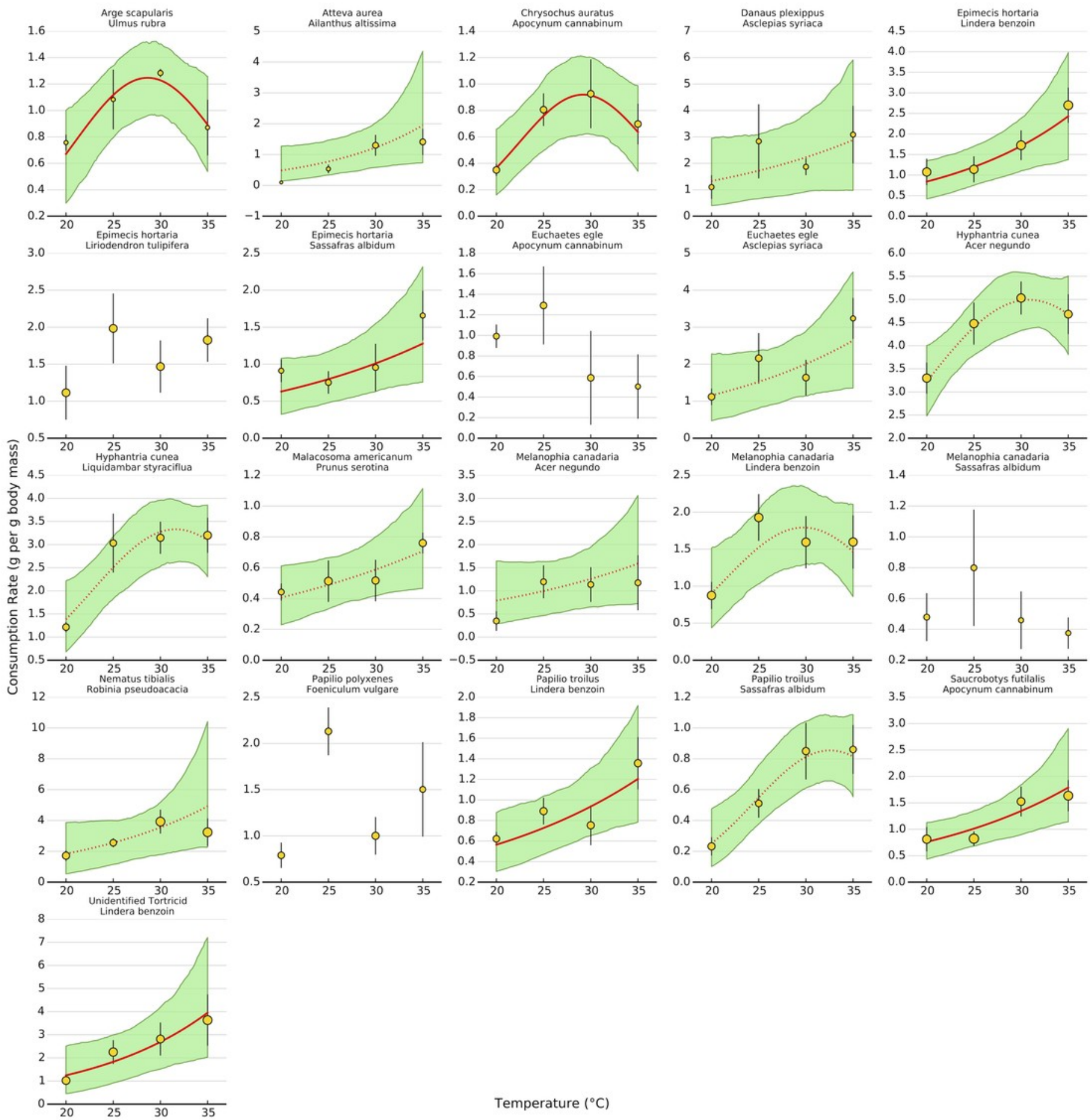

Temperature $\left({ }^{\circ} \mathrm{C}\right)$ 


\section{Figure 5}

\section{Parameter estimates for each herbivore-plant pair}

Posterior estimates of the parameters of curve-level consumption rates. Points represent the median estimate, while lines show the $80 \%$ (thick line) and 95\% (thin line) $\mathrm{Cl}$.

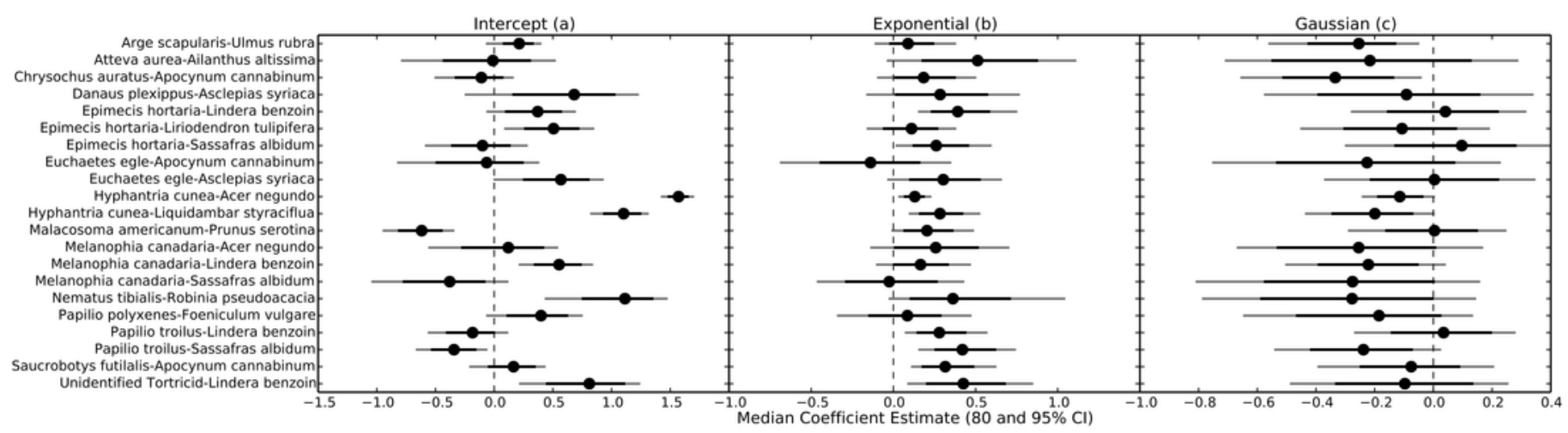




\section{Figure 6}

Parameter estimates for nutritional content effects on thermal response curves

Posterior estimates of the parameters of nutrient effects on the thermal response curves.

Points represent the median estimate, while lines show the $80 \%$ (thick line) and $95 \% \mathrm{Cl}$.

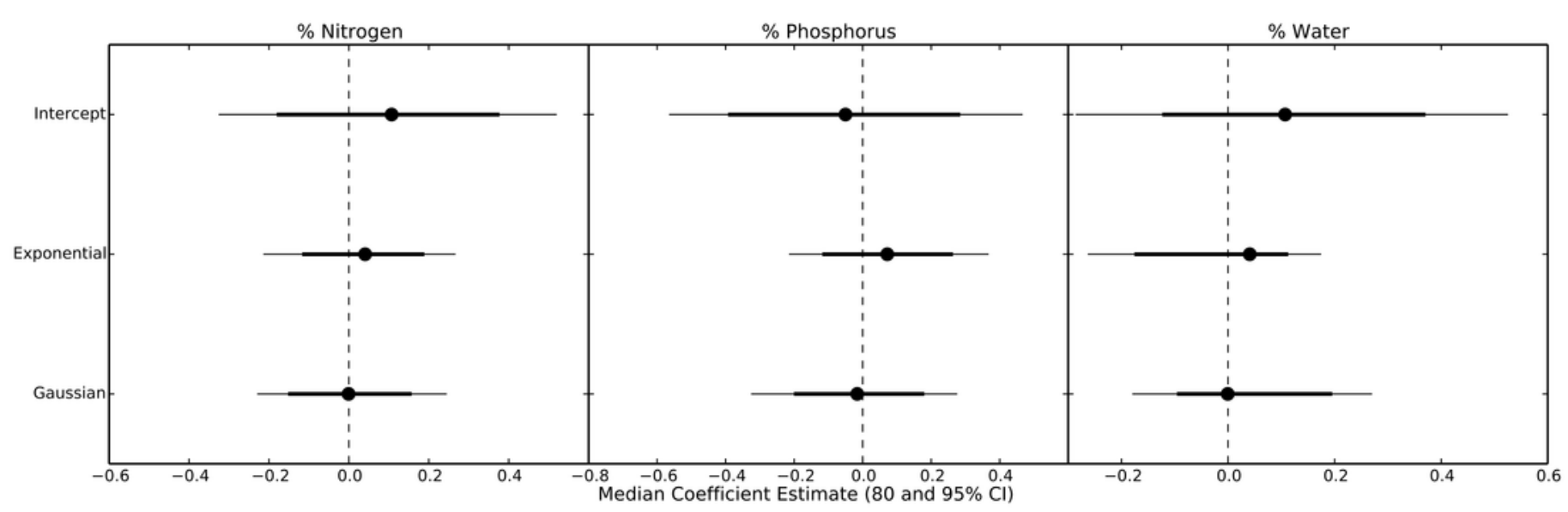




\section{Figure 7}

Change in cumulative consumption due to warming for each herbivore-plant pair

Percent change ( \pm 1 S.E.) in cumulative consumption resulting from a $3^{\circ}$ and $5^{\circ} \mathrm{C}$ increase in warming for all herbivore-plant pairs.

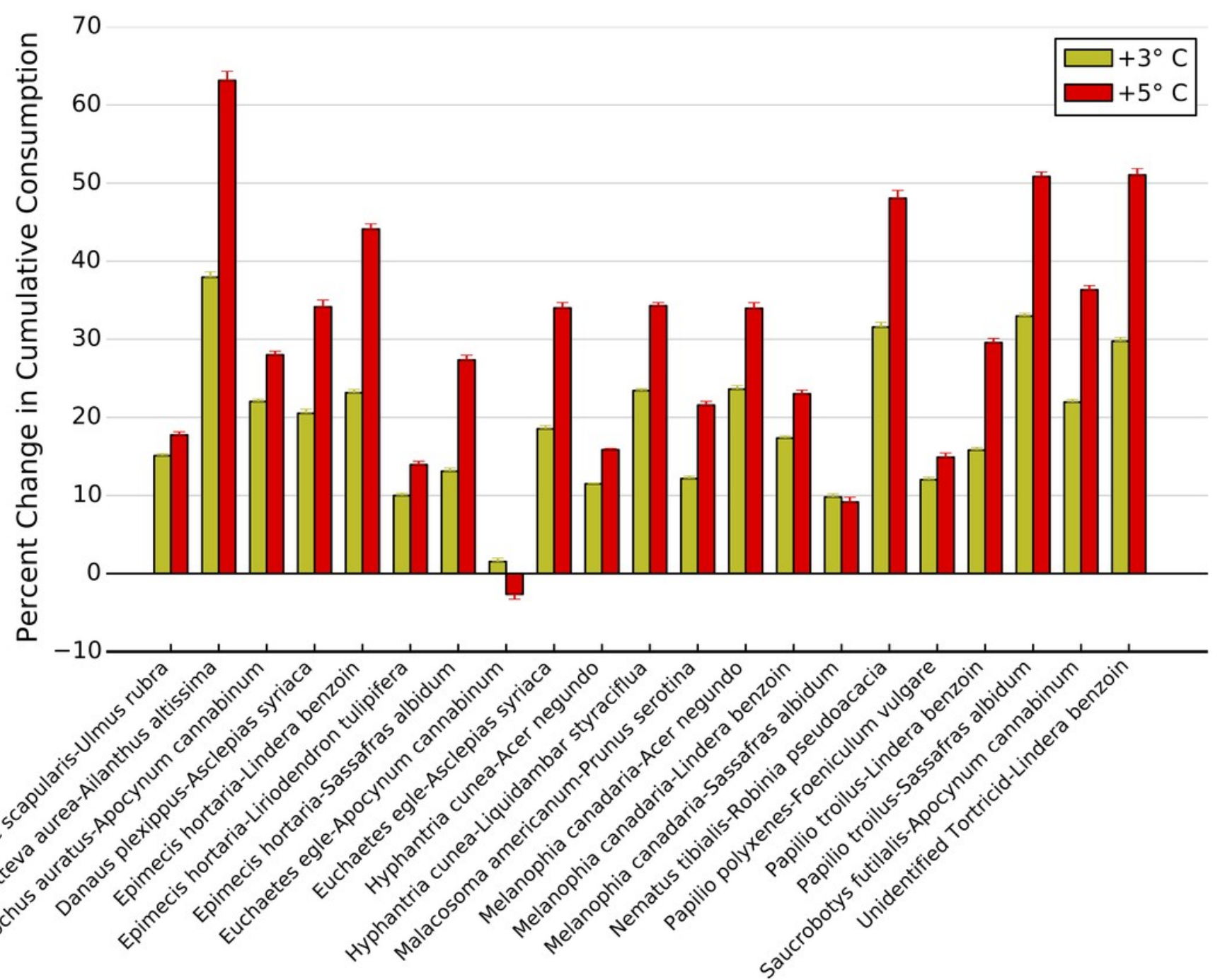




\section{Table 1 (on next page)}

Herbivores and plants used in this study

Herbivore - plant pairings used in feeding assays. Species marked with (I) are introduced species; common names are given in parentheses. Below each species name, we have listed the order and family of each species. 


\begin{tabular}{|c|c|c|}
\hline $\begin{array}{l}\text { Herbivore } \\
\text { Species }\end{array}$ & $\begin{array}{l}\text { Herbivore } \\
\text { Diet }\end{array}$ & $\begin{array}{l}\text { Plant } \\
\text { Species }\end{array}$ \\
\hline $\begin{array}{c}\text { Unidentified tortricid } \\
\text { (Lepidoptera, tortricidae) }\end{array}$ & Specialist & Lindera benzoin (northern spicebush) \\
\hline $\begin{array}{c}\text { Arge scapularis (elm argid sawfly) } \\
\text { (Hymenoptera, argidae) }\end{array}$ & Specialist & Ulmus rubra (slippery elm) \\
\hline $\begin{array}{l}\text { Atteva aurea (ailanthus webworm) } \\
\text { (Lepidoptera, yponomeutidae) }\end{array}$ & Specialist & Ailanthus altissima (tree-of-heaven) (I) \\
\hline $\begin{array}{l}\text { Chrysochus auratus (dogbane beetle) } \\
\text { (Coleoptera, chrysomelidae) }\end{array}$ & Specialist & Apocynum cannabinum (dogbane) \\
\hline $\begin{array}{l}\text { Danaus plexippus (monarch butterfly) } \\
\text { (Lepidoptera, nymphalidae) }\end{array}$ & Specialist & Asclepias syriaca (common milkweed) \\
\hline \multirow{3}{*}{$\begin{array}{l}\text { Epimecis hortaria (tulip tree beauty) } \\
\text { (Lepidoptera, geometridae) }\end{array}$} & \multirow{3}{*}{ Generalist } & Lindera benzoin (northern spicebush) \\
\hline & & Liriodendron tulipifera (tulip poplar) \\
\hline & & Sassafras albidum (sassafras) \\
\hline $\begin{array}{l}\text { Euchaetes egle (milkweed tussock moth) } \\
\text { (Lepidoptera, arctiidae) }\end{array}$ & Specialist & $\begin{array}{l}\text { Apocynum cannabinum (dogbane) } \\
\text { Asclepias syriaca (common milkweed) }\end{array}$ \\
\hline $\begin{array}{c}\text { Hyphantria cunea (fall webworm) } \\
\text { (Lepidoptera, arctiidae) }\end{array}$ & Generalist & Acer negundo (box elder) \\
\hline $\begin{array}{l}\text { Malacosoma americanum (eastern tent caterpillar) } \\
\text { (Lepidoptera, lasiocampidae) }\end{array}$ & Generalist & Prunus serotina (black cherry) \\
\hline \multirow{3}{*}{$\begin{array}{c}\text { Melanophia canadaria (canadian melanophia) } \\
\text { (Lepidoptera, geometridae) }\end{array}$} & \multirow{3}{*}{ Generalist } & Acer negundo (box elder) \\
\hline & & Lindera benzoin (northern spicebush) \\
\hline & & Sassafras albidum (sassafras) \\
\hline $\begin{array}{c}\text { Nematus tibialis (locust sawfly) } \\
\text { (Hymenoptera, tenthredinidae) }\end{array}$ & Specialist & Robinia pseudoacacia (black locust) \\
\hline $\begin{array}{l}\text { Papilio polyxenes (black swallowtail) } \\
\text { (Lepidoptera, papilionidae) }\end{array}$ & Specialist & Foeniculum vulgare (fennel) \\
\hline $\begin{array}{l}\text { Papilio troilus (spicebush swallowtail) } \\
\text { (Lepidoptera, papilionidae) }\end{array}$ & Specialist & $\begin{array}{c}\text { Lindera benzoin (northern spicebush) } \\
\text { Sassafras albidum (sassafras) }\end{array}$ \\
\hline $\begin{array}{l}\text { Saucrobotys futilalis (dogbane webworm) } \\
\text { (Lepidoptera, crambidae) }\end{array}$ & Specialist & Apocynum cannabinum (dogbane) \\
\hline
\end{tabular}

